\title{
Evidence for the involvement of sphingosine-1-phosphate in the homing and engraftment of hematopoietic stem cells to bone marrow
}

\author{
Mateusz Adamiak ${ }^{1}$, Sylwia Borkowska ${ }^{1}$, Marcin Wysoczynski ${ }^{2}$, Malwina Suszynska $^{1}$, \\ Magda Kucia'1,3, Gregg Rokosh², Ahmed Abdel-Latif ${ }^{4}$, Janina Ratajczak ${ }^{1}$, Mariusz Z. \\ Ratajczak ${ }^{1,3}$ \\ ${ }^{1}$ Stem Cell Institute at James Graham Brown Cancer Center, University of Louisville, Louisville, KY, USA \\ ${ }^{2}$ Institute of Molecular Cardiology, University of Louisville, Louisville, KY, USA \\ ${ }^{3}$ Department of Regenerative Medicine, Medical University of Warsaw, Warsaw, Poland \\ ${ }^{4}$ Division of Cardiovascular Medicine, Gill Heart Institute, University of Kentucky, Lexington, KY, USA
}

Correspondence to:

Mariusz Z. Ratajczak, e-mail: mzrata01@louisville.edu

Keywords: Pathology Section, SIP, SDF-1, CXCR4, stem cell homing, hematopoietic stem cells

Received: June 09,2015 Accepted: July 07, 2015 Published: July 17, 2015

\section{ABSTRACT}

The a-chemokine stromal-derived factor 1 (SDF-1), which binds to the CXCR4 receptor, directs migration and homing of $\mathrm{CXCR4}^{+}$hematopoietic stem/progenitor cells (HSPCs) to bone marrow (BM) stem cell niches. Nevertheless, it is also known that CXCR4 ${ }^{-/-}$fetal liver-derived hematopoietic stem cells engraft into BM and that blockade of CXCR4 by its antagonist AMD3100 does not prevent engraftment of HSPCs. Because of this finding of SDF-1-CXCR4-independent BM homing, the unique role of SDF-1 in HSPC homing has recently been challenged. While SDF-1 is the only chemokine that chemoattracts HSPCs, other chemoattractants for these cells have recently been described, including the bioactive phosphosphingolipid sphingosine-1phosphate (S1P). To address the potential role of S1P in homing of HSPCs to BM, we performed hematopoietic transplants into mice deficient in BM-expressed sphingosine kinase 1 (Sphk1 $1^{-/}$) using hematopoietic cells from normal control mice as well as cells from mice in which floxed CXCR4 (CXCR4 ${ }^{\mathrm{f} / \mathrm{fl}}$ ) was conditionally deleted. We observed the presence of a homing and engraftment defect in HSPCs of Sphk1 ${ }^{-/-}$mice that was particularly profound after transplantation of CXCR4 ${ }^{-/-}$BM cells. Thus, our results indicate that BM-microenvironment-expressed S1P plays a role in homing of HSPCs. They also support the concept that, in addition to the SDF-1-CXCR4 axis, other chemotactic axes are also involved in homing and engraftment of HSPCs.

\section{INTRODUCTION}

Stromal-derived factor 1 (SDF-1), which binds to the seven-transmembrane-spanning $\mathrm{G}_{\alpha \mathrm{I}}$ proteincoupled receptor CXCR4, is unique among the family of chemokines, because it chemoattracts hematopoietic stem/progenitor cells (HSPCs) [1-3]. Since the CXCR4 receptor is expressed on HSPCs, SDF-1 plays an important role in regulating the trafficking of these cells and facilitates their homing and engraftment in BM after transplantation. Furthermore, SDF-1 is involved in the subsequent retention of HSPCs in BM stem cell niches [3-6].
Nevertheless, the role of the SDF-1-CXCR4 axis in stem cell homing to BM has been recently challenged by several observations that support the involvement of SDF-1-CXCR4-independent homing mechanisms [7-9]. This evidence is based on observations that i) $\mathrm{CXCR} 4^{--}$ fetal liver HSPCs home to BM in an SDF-1-independent manner [7], ii) homing of murine HSPCs made refractory to SDF-1 by incubation and co-injection with a CXCR4 receptor antagonist (AMD3100) is normal or only mildly reduced [8], and iii) HSPCs in which CXCR4 has been knocked down by means of an SDF-1 intrakine strategy are still able to engraft [9]. It is also known that iv) myeloablative conditioning for transplantation induces 
a highly proteolytic microenvironment in BM that leads to proteolytic degradation of SDF-1 and thus severely attenuates its chemotactic homing gradient [10].

Evidence has accumulated that one of the most potent chemotactic factors for HSPCs is the bioactive phosphosphingolipid sphingosine-1-phosphate (S1P) [11]. An S1P gradient in PB also plays a crucial role in mobilization of HSPCs from BM into PB [11-16]. The level of S1P in BM is regulated by a balance in activity between type 1 SP-1 kinase (Sphk1) and S1P lyase, which degrades S1P. Interestingly, in the past we observed that mice in which S1P lyase is inhibited by deoxypyridoxin (DOP) display an impaired release of HSPCs from BM to $\mathrm{PB}$ in response to mobilizing agents $[11,16]$. This suggested the involvement of S1P in retention of HSPCs in BM. Based on this finding, we hypothesized that S1P plays a role also in homing and engraftment of HSPCs to BM and is involved in SDF-1-independent homing [10-12] what has been subsequently supported by observation that Sphk1-KO mice engraft poorly with WT BM cells exposed to AMD3100 [16]. To address this issue more directly and to shed more light on the role of BM-expressed S1P in the homing process, we performed homing experiments in Sphk1-deficient mice, transplanting these animals with wild type (WT) or CXCR4 ${ }^{-/-} \mathrm{HSPCs}$ [17].

We report here a defect in homing as well as engraftment of WT and, in particular, CXCR $4^{--} \mathrm{HSPCs}$ in $\mathrm{Sphk}^{-/}$mice. Thus, our data indicate that BMmicroenvironment-expressed S1P plays a role in the homing of HSPCs and supports the concept that other chemotactic axes in addition to the SDF-1-CXCR4 axis are involved in homing and engraftment of HSPCs.

\section{RESULTS}

\section{Normal steady-state hematopoiesis in Sphk1 ${ }^{-/-}$mice}

Since Sphk1 is the main BM-expressed isoform of Sphk, we became interested in the basic hematopoietic parameters of animals that lack expression of this enzyme. Figure 1A, 1B shows that Sphk $1^{-/-}$animals, in comparison with WT controls, display normal peripheral blood counts in all three major hematopoietic lineages. Moreover, these animals also have normal numbers of Sca- $1^{+} \mathrm{c}-\mathrm{kit}^{+} \mathrm{Lin}^{-}$ (SKL) cells enriched for HSPCs in BM (Figure 1C). Furthermore, by employing in vitro clonogenic assays, we found that BM cells isolated from Sphk $1^{-1-}$ mice grow similar numbers of CFU-GM, BFU-E, and CFU-Meg colonies as normal control mice (Figure 1D).

\section{Defective homing of WT BM cells in Sphk1 ${ }^{-/-}$mice}

Homing or lodging of HSPCs to BM after transplantation precedes their engraftment and expansion in the hematopoietic microenvironment [3-6]. To study the homing process of HSPCs in Sphk $1^{-/-}$animals, we transplanted BM cells isolated from green fluorescent protein (GFP) mice into lethally irradiated normal control or Sphk1 $1^{-/}$animals. Twenty-four hours after transplantation, the mice were sacrificed, and we evaluated the number of $\mathrm{GFP}^{+}$cells in BM by FACS (Figure 2A) and the number of clonogenic progenitors that lodged during this time to $\mathrm{BM}$, and we were able to grow in vitro $\mathrm{GFP}^{+}$colonies after isolation from the long bones (Figure 2B). We found that Sphk1 $1^{-/-}$mice had significantly lower numbers of $\mathrm{GFP}^{+}$cells and $\mathrm{GFP}^{+}$clonogeneic progenitors in $\mathrm{BM}$ compared with normal control animals.

\section{A defect in short-and long-term BM engraftment of HSPCs in Sphk1 ${ }^{-/}$animals}

The outcome of a hematopoietic transplant is a function of homing/lodging efficiency and the number of transplanted cells. To study the role of BM-expressed S1P in the homing of HSPCs, we transplanted into Sphk1 $1^{-/}$mice normal control BM cells as well as $\mathrm{CXCR} 4^{\mathrm{f} / \mathrm{fl}} \mathrm{BM}$ cells in which expression of CXCR4 had been efficiently deleted by Cre-recombinase [17]. Our preliminary results indicated that the chemotactic responsiveness of normal control and $\mathrm{CXCR}^{-/-} \mathrm{BM}$ clonogenic progenitors to S1P gradients was similar (Supplementary Figure S1).

Thus, we transplanted normal BM cells into normal (control) mice or Sphk1 $1^{-/}$animals and evaluated the number of day-11 CFU-GM colonies present in BM as well as the number of day-11 spleen colonies formed by CFU-S (Figure 3A) and found impaired homing of HSPCs to BM in Sphk1 $1^{-/-}$mice. Similar and even more profound defects in the number of day-11 CFU-GM colonies and day-11 CFU-S colonies were observed after transplantation of $\mathrm{CXCR}^{-/-} \mathrm{BM}$ cells (Figure 3B).

Based on these results, we transplanted normal BM cells or $\mathrm{CXCR}^{-/-} \mathrm{BM}$ cells into lethally irradiated normal or Sphk $1^{--}$mice and followed the recovery of white blood cells and platelet counts in these animals (Figure 4A, 4B). We found that Sphk $1^{-/}$animals, compared with WT mice, showed a defect in recovery of leucocytes and platelets and that this defect was more pronounced if mice were transplanted with $\mathrm{CXCR}^{-/-} \mathrm{BM}$ cells. As shown in Figure 4, the recovery of peripheral blood counts in Sphk1 $1^{-/}$ mice after transplantation of $\mathrm{CXCR} 4^{-/-}$cells was delayed by two weeks compared with normal mouse recipients.

\section{DISCUSSION}

The salient observation of this study is that BMexpressed S1P is involved in homing and engraftment of HSPCs to BM. Despite the fact that the SDF-1-CXCR4 axis is crucial for retention of HSPCs in BM niches and that Sphk1 ${ }^{-/-}$mice do not show any hematopoietic defects under steady-state conditions, our results support the involvement of S1P in this process and the existence of an SDF-1-independent, S1P-mediated homing mechanism. 

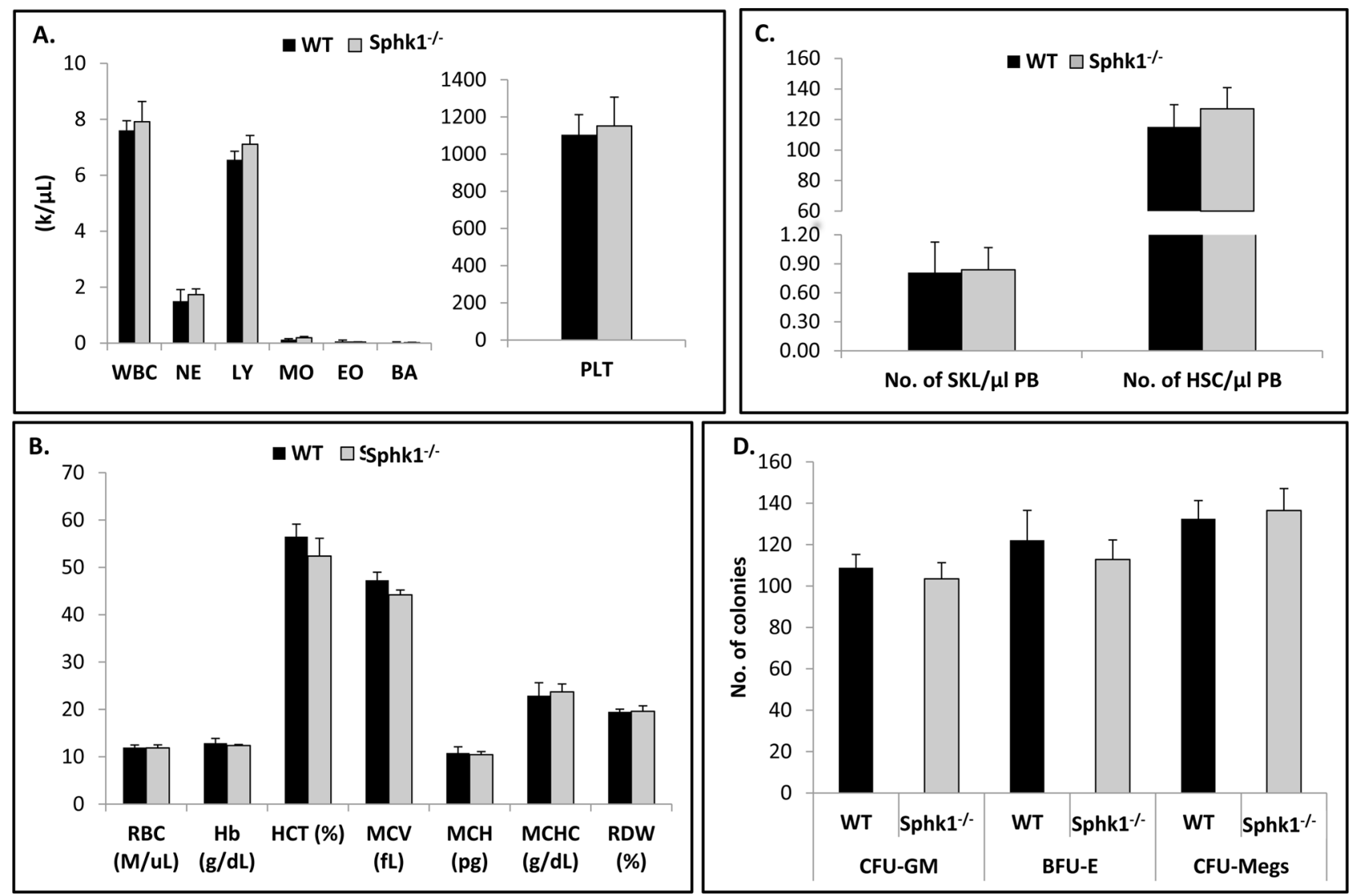

Figure 1: Sphk1 deficiency does not affect hematological homeostasis. Bone marrows of WT and Sphk1 $1^{-\digamma}$ mice were isolated and evaluated for peripheral blood white blood cell A. and red blood cell B. parameters as well as the number of SKL cells in BM C. and in vitro clonogenic progenitor cells $\mathbf{D}$. The data represent an average of at least six mice per experimental group.
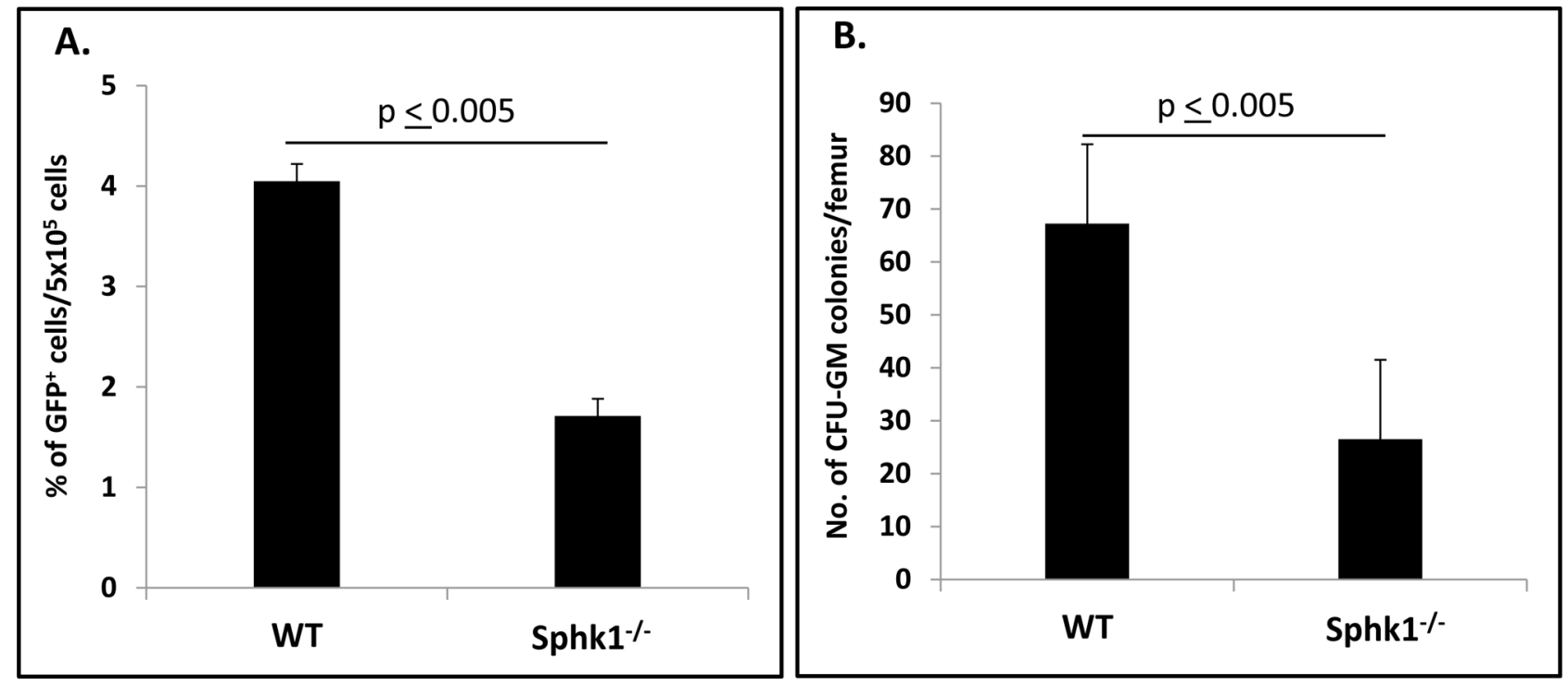

Figure 2: A defect in homing of HSPCs from GFP $^{+}$mice in Sphk1 ${ }^{-/}$BM. Panel A. Lethally irradiated Sphk $1^{-/}$mice (six mice per group) were transplanted with $5 \times 10^{6} \mathrm{GFP}^{+}$bone marrow mononuclear cells (BMMNCs); 24 hours after transplantation femoral BMMNCs were harvested; the number of $\mathrm{GFP}^{+}$cells in murine BM was evaluated by FACS (panel A); and the number of clonogenic $\mathrm{GFP}^{+}$CFU-GM progenitors was enumerated in an in vitro colony assay (panel B). No colonies were formed in lethally irradiated and nontransplanted mice (irradiation control). The data in panels A and B represent the combined results from two independent experiments $(n=$ 10). ${ }^{*} p<0.005$. 


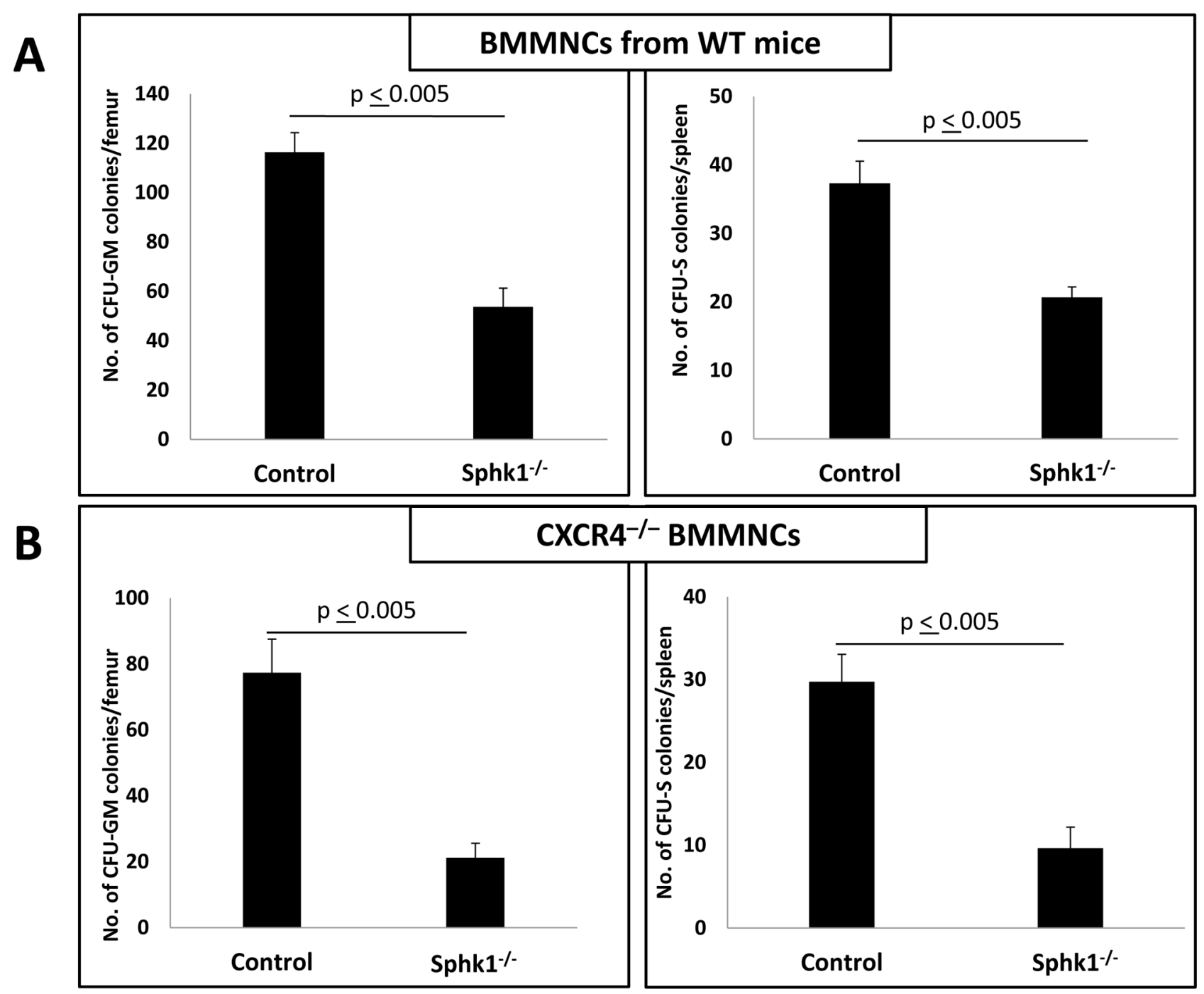

Figure 3: A defect in short-term engraftment of WT and CXCR4 ${ }^{-/-}$HSPCs in Sphk1 ${ }^{-/-}$BM. Panel A. Lethally irradiated mice (six mice per group) were transplanted with $1.5 \times 10^{5}$ bone marrow mononuclear cells (BMMNCs) from WT mice, and 11 days after transplantation spleens were removed and femoral BMMNCs were harvested for counting the number of CFU-S colonies and plating to count the number of CFU-GM colonies, respectively. Panel B. In similar experiments, mice were lethally irradiated and transplanted with $1.5 \times 10^{5} \mathrm{BMMNCs}$ from $\mathrm{CXCR} 4^{-/}$mice. Eleven days after transplantation, spleens were removed and femoral BMMNCs were harvested for counting the number of CFU-S colonies and plating to count the number of CFU-GM colonies, respectively. The data in panels A and $\mathrm{B}$ represent the combined results from three independent experiments $(n=9)$. $* p<0.005$.

Overall, the developmental and postnatal migration of HSPCs is still not well understood. HSPCs migrate during embryonal development, colonizing different organs where hematopoiesis is initiated. In the second trimester of gestation, they colonize fetal liver, which is a major hematopoietic organ at this stage of development [18-20]. Despite the fact that SDF-1 is considered to be the most important factor regulating migration of HSPCs, surprisingly, murine embryos with CXCR4 or SDF-1 knocked out have a normal number of myeloid HSPCs in fetal liver [21-24]. Because fetal liver is colonized by HSPCs migrating from the aorta-gonad-mesonephros (AGM) region, this result suggests that this process is mediated by chemoattractants other than SDF-1 [21-24].
Moreover, as mentioned in the introduction, HSPCs isolated from $\mathrm{CXCR}^{-/-}$murine fetal liver home to $\mathrm{BM}$ in an SDF-1-independent manner [7], and it is also well known that homing of murine HSPCs made refractory to SDF-1 by incubation and co-injection with a CXCR4 receptor antagonist (AMD3100) is normal or only mildly reduced [8]. Finally, as we demonstrate here, CXCR4 ${ }^{-/-}$ $\mathrm{BM}$ cells generated by a Cre-recombinase strategy also home to BM after transplantation, although the timing of the homing and engraftment process is delayed.

All this supports the conclusion that, in addition to the SDF-1-CXCR4 axis, additional redundant mechanisms exist. Taking all this into consideration, we focused our investigation on the potential role of S1P. 

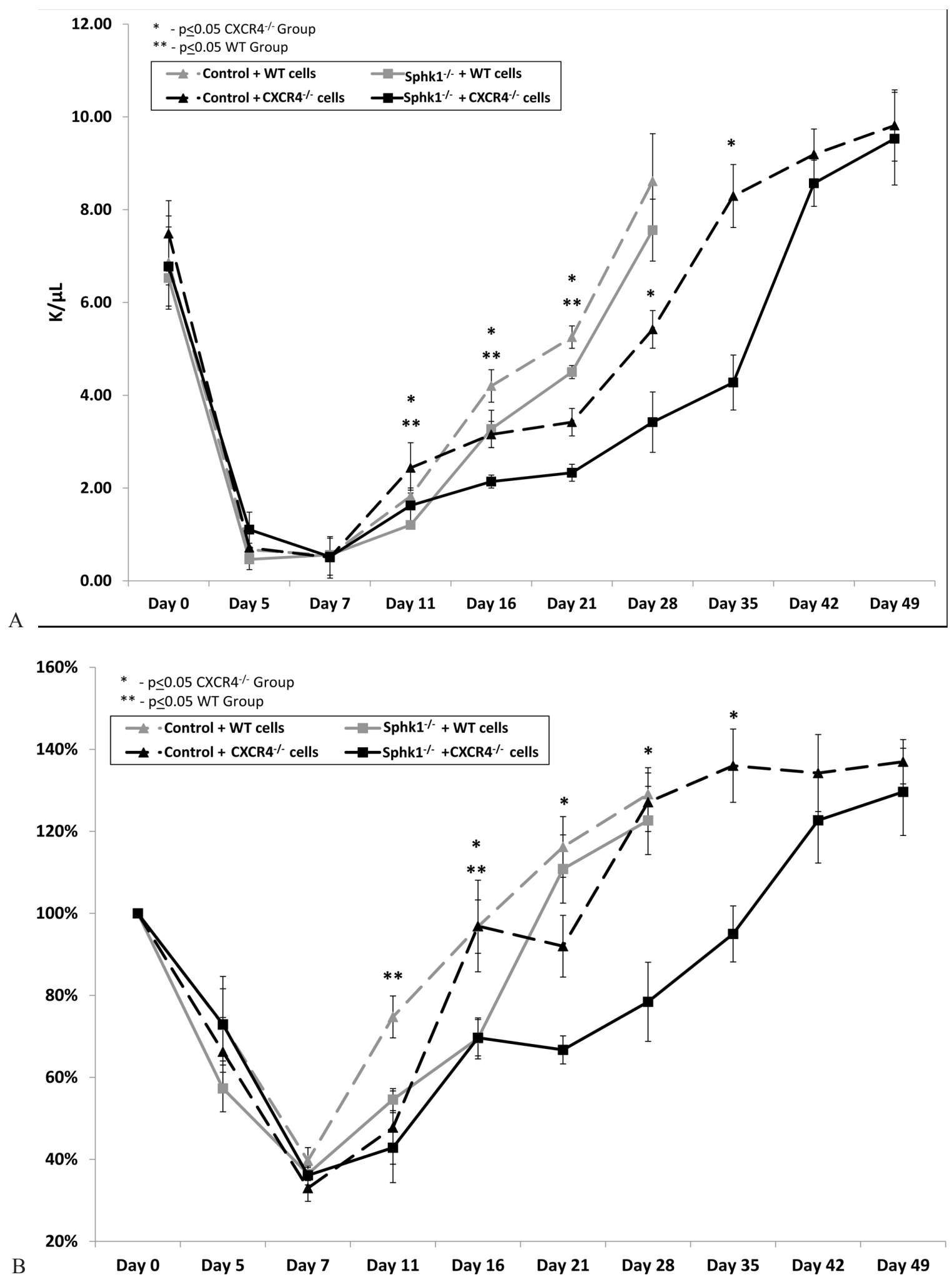

Figure 4: A defect in long-term engraftment of WT and CXCR4 ${ }^{-/-}$HSPCs in Sphk1 $1^{-/-}$BM. Lethally irradiated Sphk $1^{-/-}$mice were transplanted with $1 \times 10^{6}$ BMMNCs from WT or CXCR4 $4^{--}$cells. White blood cells (panel A) and platelets (panel B) were counted at intervals (at $0,5,7,11,16$, and 21 days and, for CXCR4 $4^{-/}$transplant, additionally at $28,35,42$, and 49 days after transplantation). For platelets count changes have been shown in \% in comparison to day 0 for which platelet counts were assumed to be $100 \%$. Results are combined from two independent experiments (six mice per group, $n=12$ ). ${ }^{*} p<0.05$. 
This phosphosphingolipid is a potent chemoattractant for HSPCs, even more potent than SDF-1 if employed at the physiological doses that are encountered in biological fluids [11]. Because of its chemical structure, $\mathrm{S} 1 \mathrm{P}$, in contrast to peptide-based SDF-1, is resistant, to destruction by proteolytic enzymes, which are highly upregulated in the $\mathrm{BM}$ microenvironment when it is irradiated or conditioned by chemotherapy [10]. S1P has been demonstrated to be involved in trafficking of HSPCs, and, as recently demonstrated by us and others, $\mathrm{S} 1 \mathrm{P}$ present in PB is involved in egress of HSPCs from $\mathrm{BM}$ during the mobilization process [11-16].

Interestingly, our previous research demonstrated that mobilization of HSPCs is impaired in mice after inhibition of S1P lyase, which degrades S1P and thus increases its level in BM [25]. This observation, along with the fact that S1P is upregulated after conditioning for transplantation in the BM microenvironment [11], prompted us to study its role in the homing process.

We report here that $\mathrm{Sphk} 1^{-/-}$mice, deficient in S1P level in BM, display impaired homing of transplanted HSPCs. Since these mice have a normal level of SDF-1 in BM, the lack of S1P in the hematopoietic microenvironment was compensated after transplantation of normal control BM cells by chemoattraction through the SDF-1-CXCR4 axis. However, if we performed transplants into $\mathrm{Sphk}^{-/}$mice employing $\mathrm{CXCR}^{-/-} \mathrm{BM}$ cells, we observed delayed long-term engraftment of the transplanted cells, and this experiment revealed the importance of the S1P homing mechanism.

However, the fact that $\mathrm{CXCR} 4^{-/}$cells were finally able to engraft in $\mathrm{Sphk}^{-/-}$mice suggests the existence of other chemoattractants that are involved in this process in addition to SDF-1 and S1P. In support of this inference, it has been demonstrated that another bioactive phosposphingolipid, ceramide-1-phosphate (C1P), is also a potent chemoattractant for HSPCs [10]. We have reported that, like the $\mathrm{S} 1 \mathrm{P}$ level, the $\mathrm{C} 1 \mathrm{P}$ level is also increased in BM after myeloablative conditioning for transplantation $[10,11]$. The problem with studying the possible involvement of $\mathrm{C} 1 \mathrm{P}$ in the homing process is that the receptor/s for $\mathrm{C} 1 \mathrm{P}$ has not yet been identified, and thus the appropriate murine knockout experimental models are not available.

Other potential factors involved in the homing process are extracellular nucleotides such as ATP or UTP [26-28]. We have recently reported that the concentration of extracellular nucleotides also increases in BM after irradiation $[29,30]$. Thus, it would be interesting to see the effect of extracellular nucleotide receptor blockage on homing and engraftment of HSPCs, and we are currently planning such experiments.

Despite the fact that some crucial chemotactic factors for HSPCs, including SDF-1, S1P, C1P, and extracellular nucleotides (e.g., ATP and UTP), have been identified, we cannot exclude the possibility that there are other molecules and mechanisms involved in homing that could compensate for an SDF-1-CXCR4 axis deficiency. For example, the involvement of $\mathrm{Ca} 2^{+}-$ sensing mechanisms in the migration of HSPCs has been described [31]. A similar $\mathrm{H}^{+}$-sensing mechanism could also be involved, but this requires further study.

It is well known that SDF-1 can also bind to the CXCR7 receptor, but the involvement of the SDF1-CXCR7 axis in the homing of HSPCs is based on inconclusive evidence. Nevertheless, it would be interesting to perform homing experiments in Sphk $1^{-/-}$ animals with HSPCs in which both CXCR4 and CXCR7 receptors are eliminated from the cell surface. An alternative strategy would be to perform transplant experiments into Sphk $1^{-/-}$mice in which stromal SDF-1 is conditionally knocked out.

An important question is how conditional CXCR4 knockout BM cells engrafted in our mouse models could be theoretically explained by an SDF-1 priming phenomenon [32]. It is known that several soluble factors released during conditioning for transplantation, including elements of innate immunity, such as cleavage fragments of C3 [33]; cationic antimicrobial peptides, such as cathelicidin (LL-37) [34] and $\beta 2$-defensin [35]; and prostaglandin E2 (PGE2) [36], a member of the eicosanoid family, significantly enhance responsiveness of the SDF1-CXCR4 axis. However, since CXCR4 was deleted by $\sim 99 \%$ by Cre-recombinase in the HSPCs employed in our experiments, SDF-1 priming effects are most likely not involved.

In these experiments we did not address which of the $\mathrm{S} 1 \mathrm{P}$ receptors is most crucial for the observed phenomena, but, based on the responsiveness of HSPCs to an S1P gradient, the most likely candidate in S1P-mediated homing is the $\mathrm{S} 1 \mathrm{P}$ type 1 receptor $\left(\mathrm{S}_{1} \mathrm{P}_{1} \mathrm{R}\right)$ [11-16].

In conclusion, we demonstrated a defect in homing as well as engraftment of WT HSPCs and, most importantly, $\mathrm{CXCR}^{-/-} \mathrm{HSPCs}$ in Sphk1 ${ }^{-/-}$mice. Thus, our results indicate that S1P expressed in the BM-microenvironment plays a role in homing of HSPCs and supports the concept that other chemotactic axes are involved in homing and engraftment of HSPCs in addition to the SDF-1-CXCR4 axis (Figure 5). Further studies are needed to evaluate the involvement of other potential homing factors, such as C1P, extracellular nucleotides (e.g., ATP), $\mathrm{Ca}^{2+}$ sensing mechanism, PGE2 involvement and a role of hyaluronic acid - CD44 interaction [11, 12, 27, 31, 36, 39-42], that may compensate for SDF-1-and S1P-mediated homing.

\section{MATERIAL AND METHODS}

\section{Animals}

Sphk1 $1^{-/-}$6-8-week-old mice and age-and sex-matched littermates, all employed in homing experiments, as well as green immunofluorescence protein (GFP)-expressing mice 


\section{Bone Marrow}

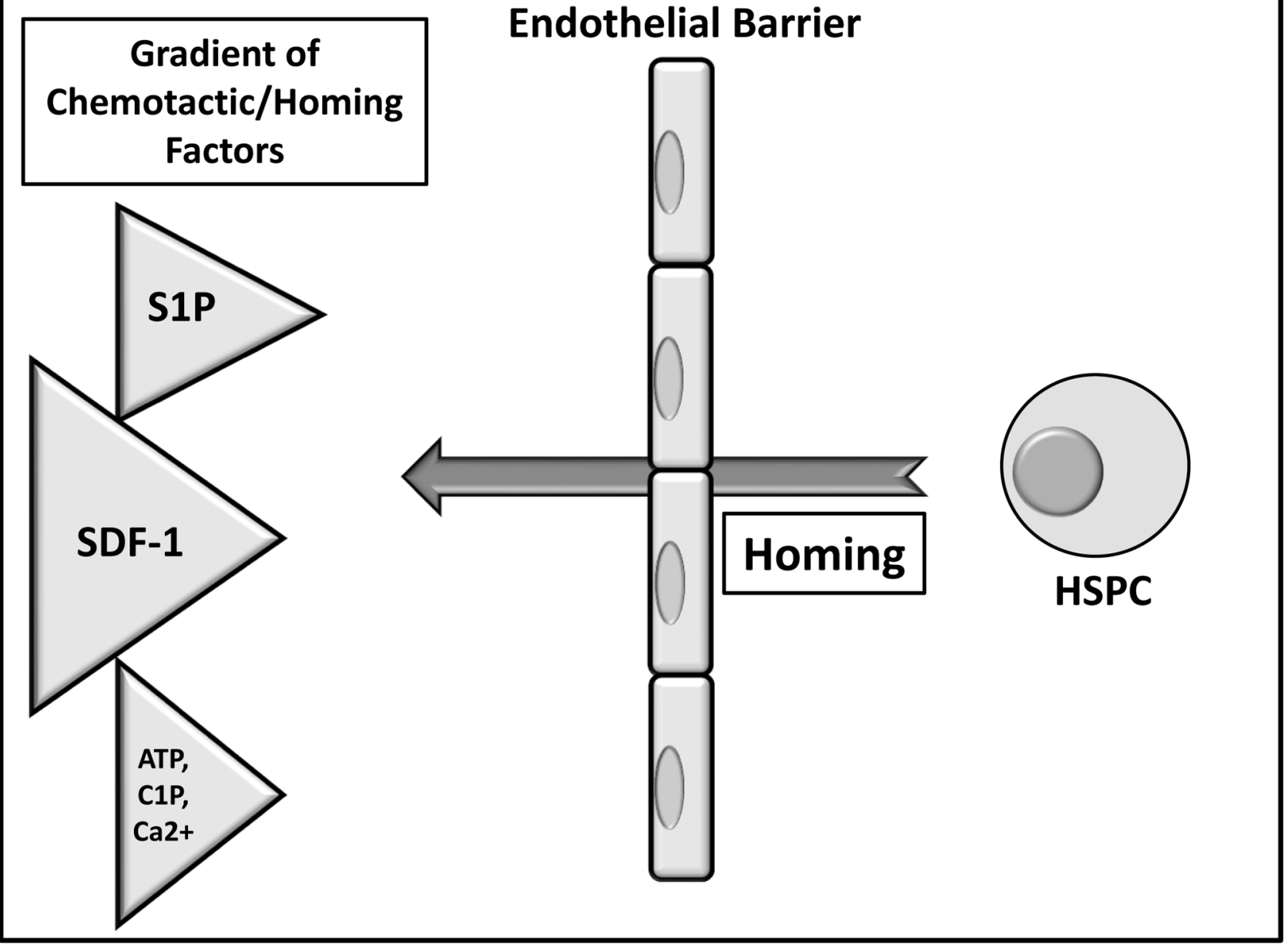

\section{Peripheral Blood}

Figure 5: The proposed major mechanism underlying the processes of homing of HSPCs. HSPCs infused into blood respond to a gradient of SDF-1 between bone marrow and blood; however, conditioning for transplantation by chemoradiotherapy may also upregulate other homing factors, such as S1P and C1P, and increase the levels of extracellular nucleotides (ATP and UTP). Homing is also regulated by $\mathrm{Ca}^{2+}$ gradient in the BM microenvironment. Most likely, there are also other unidentified yet factors involved in the homing process.

were purchased from The Jackson Laboratory, Bar Harbor, ME. Cxcr4 ${ }^{\text {fl/fl }}$ mice (provided by Dr. Yong-Rui Zou, The Feinstein Institute for Medical Research) were crossed with B6.Cg-Tg(UBC-cre/ERT2)1Ejb/J mice (Jackson Labolatory) to generate $\mathrm{CXCR} 4{ }^{\mathrm{f} / \mathrm{ll}} \mathrm{Cre}^{\mathrm{Tg} /-}$ mice [17]. To delete Cxcr4, mice were injected intraperitoneally with tamoxifen (80 mg/kg/day, Sigma-Aldrich) for five consecutive days. The efficiency of recombination was evaluated in peripheral blood and bone marrow after the last tamoxifen injection and was greater than $99 \%$. Animal studies were approved by the Animal Care and Use Committee of the University of Louisville (Louisville, KY).

\section{Peripheral blood (PB) parameter counts}

To obtain leukocyte and red blood cells counts, 50 microliters of $\mathrm{PB}$ were taken from the retro-orbital plexus of the mice into EDTA-coated Microvette tubes
(Sarstedt Inc., Newton, NC, USA) and run within $2 \mathrm{~h}$ of collection on a HemaVet 950FS hematology analyzer (Drew Scientific Inc., Oxford, CT, USA) as described [11].

\section{FACS analysis}

The following monoclonal antibodies were employed to perform analytical staining of $\mathrm{Lin}^{-} / \mathrm{Sca}-$ $1^{+} / \mathrm{c}^{-\mathrm{kit}^{+}}$(SKL cells) and $\mathrm{Lin}^{-} / \mathrm{Sca}-1^{+} / \mathrm{CD} 45^{+}$(HSCs): fluorescein isothiocyanate (FITC) anti-CD117 (c-kit) (clone2B8; BioLegend, San Diego, CA) and phycoerythrin (PE)-Cy5 anti-mouse Ly-6A/E (Sca-1) (clone D7; eBioscience $^{\mathrm{TM}}$, San Diego, CA). All anti-mouse lineage markers (Lin) were conjugated with $\mathrm{PE}$ and purchased from BD Biosciences: anti-CD45R/B220 (clone RA36B2); anti-Ter-119 (clone TER-119); anti-CD11b (clone M1/70); anti-T-cell receptor $\beta$ (TCR $\beta$; clone H57-597); 
anti-Gr-1 (clone RB6-8C5); anti-TCR $\gamma \delta$ (clone GL3); and anti-CD45 (clone 30-F11). All monoclonal antibodies were added at saturating concentrations, and the cells were then incubated for $30 \mathrm{~min}$ on ice, washed twice, resuspended in RPMI-1640 plus 2\% fetal bovine serum, and analyzed with an LSR II flow cytometer (BD, San Diego, CA, USA) [11].

\section{Clonogenic in vitro assay}

After red blood cells (RBCs) from PB were lysed (Pharm Lyse buffer, BD Biosciences, San Jose, CA), the nucleated cells were subsequently washed twice and used for CFU-GM colony formation, and cells were counted and resuspended in human methylcellulose base media provided by the manufacturer (R\&D Systems, Inc., Minneapolis, MN), supplemented with $25 \mathrm{ng} / \mathrm{ml}$ recombinant murine granulocyte macrophage colony-stimulating factor (mGM-CSF) and $10 \mathrm{ng} / \mathrm{ml}$ recombinant murine interleukin 3 (mIL-3; Millipore, Billerica, MA). Cultures were incubated for 7 days and then scored for the number of CFU-GM colonies under an inverted microscope. We cultured $1 \times 10^{6}$ peripheral blood mononuclear cells (PBMNCs)/ dish, and final results were recalculated based on the number of PBMNCs per $1 \mu \mathrm{l}$ of PB. Each clonogenic test was performed in duplicate. To evaluate the number of clonogenic progenitor cells, bone marrow mononuclear cells (BMMNCs) were supplemented with erythropoietin (EPO, 5 unit/ml, Stem Cell Tech) plus stem cell factor $(\mathrm{SCF}, 5 \mathrm{ng} / \mathrm{ml})$, resuspended in methylcellulose base medium for burst-forming units (BFU-E), supplemented with thrombopoietin (TPO, $100 \mathrm{ng} / \mathrm{ml}$ ) plus interleukin-3 (mIL-3, $10 \mathrm{ng} / \mathrm{ml}$ ), and resuspended in plasma cloth cultures for determining the number of CFU-megakaryocytes (Megs) and CFU-GM colonies, performed as above. Cultures were incubated for 7 days $\left(37^{\circ} \mathrm{C}, 95 \%\right.$ humidity, and $\left.5 \% \mathrm{CO}_{2}\right)$, at which time they were scored under an inverted microscope for the number of colonies, as described [11].

\section{Short-term homing experiments}

Mice were irradiated with a lethal dose of $\gamma$-irradiation (1000 cGy). After $24 \mathrm{~h}$, the animals were transplanted (by tail vein injection) with $5 \times 10^{6} \mathrm{BM}$ cells from GFP mice. At $24 \mathrm{~h}$ after transplant, BM cells from the femurs were isolated via Ficoll-Paque and divided. Some cells $\left(5 \times 10^{5}\right)$ were incubated with Vybrant ${ }^{\circledR}$ DyeCycle ${ }^{\mathrm{TM}}$ Ruby stain (Invitrogen, CA) and analyzed on a flow cytometer. The rest of the cells were plated in serum-free methylcellulose cultures and stimulated to grow CFU-GM colonies with granulocyte macrophage-colony stimulating factor (GM-CSF, $25 \mathrm{ng} / \mathrm{ml}$ ) and interleukin 3 (IL-3, 10 $\mathrm{ng} / \mathrm{ml})$. After 7 days of incubation $\left(37^{\circ} \mathrm{C}, 95 \%\right.$ humidity, and $5 \% \mathrm{CO}_{2}$ ) the number of colonies was scored under an inverted microscope [37].

\section{Evaluation of engraftment}

For engraftment experiments, mice were irradiated with a lethal dose of $\gamma$-irradiation (1000 cGy). After 24 $\mathrm{h}$, mice were transplanted with $1.5 \times 10^{5} \mathrm{BM}$ cells from WT or $\mathrm{Cxcr}^{-/-}$mice by tail vein injection. Femora of transplanted mice were flushed with phosphate-buffered saline (PBS) on day 12 post-transplant. Purified via FicollPaque, BM cells were plated in serum-free methylcellulose cultures and stimulated to grow CFU-GM colonies with G-CSF (25 ng/ml) plus IL-3 (10 ng/ml). After 7 days of incubation $\left(37^{\circ} \mathrm{C}, 95 \%\right.$ humidity, and $\left.5 \% \mathrm{CO}_{2}\right)$ the number of colonies was scored under an inverted microscope. Spleens were also removed, fixed in Telesyniczky's solution for CFU-S assays, and colonies were counted on the surface of the spleen [38].

\section{Recovery of leukocytes and platelets}

For transplantation experiments, mice were irradiated with a lethal dose of $\gamma$-irradiation (1000 cGy). After $24 \mathrm{~h}$, the mice were transplanted by tail vein injection with $1 \times 10^{6} \mathrm{BM}$ cells. Transplanted mice were bled at various intervals from the retro-orbital plexus to obtain samples for white blood cell and platelet counts as described [37].

\section{Chemotaxis assay}

BMMNCs from WT and Cxcr4 $4^{-/-}$mice at a density of $1 \times 10^{6}$ in $100 \mu \mathrm{l}$ were aliqoted into $5-\mu \mathrm{m}$ polycarbonate membrane inserts in a Costar Transwell 24-well plate (Costar Corning, Cambridge, MA, USA) for $3 \mathrm{~h}$ chemotaxis at $37^{\circ} \mathrm{C}$. Medium with $0.5 \%$ BSA $(650 \mu \mathrm{l} /$ well $)$ containing either no chemoattractant (negative control) or sphingosine1-phosphate $(0.1 \mu \mathrm{M}$, Cayman Chemical, Michigan, USA) was added to the lower chambers of the plate. Subsequently, cells in the lower chambers were harvested and assayed for the number of CFU-GM colony-forming units. Briefly, cells were resuspended in human methylcellulose base medium provided by the manufacturer (R\&D Systems), supplemented with GM-CSF (25 ng/ml) and IL-3 (10 ng/ml) for determining the number of CFU-GM colonies. Cultures were incubated for 7 days, at which time they were scored under an inverted microscope for the number of colonies [11].

\section{Statistical analysis}

All results are presented as mean \pm SD. Statistical analysis of the data was done using Student's $t$-test for unpaired samples, with $p \leq 0.05$ considered significant.

\section{ACKNOWLEDGMENTS}

This work was supported by NIH grants 2R01 DK074720 and R01HL112788 and the Stella and Henry Hoenig Endowment to MZR and University of 
Kentucky Clinical and Translational Science Pilot Award (UL1TR000117), the UK COBRE Early Career Program (P20 GM103527), and NIH Grant R56 HL124266.

\section{CONFLICTS OF INTEREST}

The authors declare they have no known conflicts of interest in this work.

\section{REFERENCES}

1. Nagasawa T. A chemokine, SDF-1/PBSF, and its receptor, CXC chemokine receptor 4 , as mediators of hematopoiesis. International Journal of Hematology. 2000; 72:408-411.

2. Ara T, Tokoyoda K, Sugiyama T, Egawa T, Kawabata K, Nagasawa T. Long-term hematopoietic stem cells require stromal cell-derived factor-1 for colonizing bone marrow during ontogeny. Immunity. 2003; 19:257-267.

3. Lapidot T, Kollet O. The brain-bone-blood triad: traffic lights for stem-cell homing and mobilization. Hematology Am Soc Hematol Educ Program. 2010; 2010:1-6.

4. Bonig H, Papayannopoulou T. Hematopoietic stem cell mobilization: updated conceptual renditions. Leukemia. $2013 ; 27: 24-31$.

5. Lévesque JP, Helwani FM, Winkler IG. The endosteal 'osteoblastic' niche and its role in hematopoietic stem cell homing and mobilization. Leukemia. 2010; 24:1979-1992.

6. Doan PL, Chute JP. The vascular niche: home for normal and malignant hematopoietic stem cells. Leukemia. 2012; 26:54-62.

7. Ma Q, Jones D, Springer TA. The chemokine receptor CXCR4 is required for the retention of B lineage and granulocytic precursors within the bone marrow microenvironment. Immunity. 1999; 10:463-471.

8. Christopherson KW, Hangoc G, Mantel CR, Broxmeyer HE. Modulation of hematopoietic stem cell homing and engraftment by CD26. Science. 2004; 305:1000-1003.

9. Onai N, Zhang YY, Yoneyama H, Kitamura T, Ishikawa S, Matsushima K. Impairment of lymphopoiesis and myelopoiesis in mice reconstituted with bone marrow-hematopoietic progenitor cells expressing SDF-1-intrakine. Blood. 2000; 96:2074-2080.

10. Kim $\mathrm{CH}, \mathrm{Wu} \mathrm{W}$, Wysoczynski $\mathrm{M}$, Abdel-Latif A, Sunkara M, Morris A, Kucia M, Ratajczak J, Ratajczak MZ. Conditioning for hematopoietic transplantation activates the complement cascade and induces a proteolytic environment in bone marrow: a novel role for bioactive lipids and soluble $\mathrm{C} 5 \mathrm{~b}-\mathrm{C} 9$ as homing factors. Leukemia. 2012; 26:106-116.

11. Ratajczak MZ, Lee H, Wysoczynski M, Wan W, Marlicz W, Laughlin MJ, Kucia M, Janowska-Wieczorek A, Ratajczak J. Novel insight into stem cell mobilizationPlasma sphingosine-1-phosphate is a major chemoattractant that directs the egress of hematopoietic stem progenitor cells from the bone marrow and its level in peripheral blood increases during mobilization due to activation of complement cascade/membrane attack complex. Leukemia. 2010; 24:976-985.

12. Ratajczak MZ, Kim CH, Abdel-Latif A, Schneider G, Kucia M, Morris AJ, Laughlin MJ, Ratajczak J. A novel perspective on stem cell homing and mobilization: review on bioactive lipids as potent chemoattractants and cationic peptides as underappreciated modulators of responsiveness to SDF-1 gradients. Leukemia. 2012; 26:63-72.

13. Seitz G, Boehmler AM, Kanz L, Möhle R. The role of sphingosine 1-phosphate receptors in the trafficking of hematopoietic progenitor cells. Annals of the New York Academy of Sciences. 2005; 1044:84-89.

14. Massberg S, von Andrian UH. Novel trafficking routes for hematopoietic stem and progenitor cells. Ann N Y Acad Sci. 2009; 1176:87-93.

15. Juarez JG, Harun $\mathrm{N}$, Thien $\mathrm{M}$, Welschinger $\mathrm{R}$, Baraz R, Pena AD, Pitson SM, Rettig M, DiPersio JF, Bradstock KF, Bendall LJ. Sphingosine-1-phosphate facilitates trafficking of hematopoietic stem cells and their mobilization by CXCR4 antagonists in mice. Blood. 2012; 119:707-716.

16. Golan K, Vagima Y, Ludin A, Itkin T, CohenGur S, Kalinkovich A, Kollet O, Kim CH, Schajnovitz A, Ovadya Y, Lapid K, Shivtiel S, Morris AJ, et al. S1P promotes murine progenitor cell egress and mobilization via S1P1-mediated ROS signaling and SDF-1 release. Blood. 2012; 119:2478-2488.

17. Yuchun N, Yoon-Chi H, Yong-Rui Z. CXCR4 is required for the quiescence of primitive hematopoietic cells. J Exp Med. 2008; 205:777-783.

18. Ciriza J, Thompson H, Petrosian R, Manilay JO, GarcíaOjeda ME. The migration of hematopoietic progenitors from the fetal liver to the fetal bone marrow: Lessons learned and possible clinical applications. Experimental Hematology. 2013; 41:411-423.

19. Baron MH. Embryonic origins of mammalian hematopoiesis. Experimental Hematology. 2003; 31:1160-1169.

20. Lux CT, Yoshimoto M, McGrath K, Conway SJ, Palis J, Yoder MC. All primitive and definitive hematopoietic progenitor cells emerging before E10 in the mouse embryo are products of the yolk sac. Blood. 2008; 111:3435-3438.

21. Nagasawa $T$, Hirota $S$, Tachibana $K$, Takakura N, Nishikawa S, Kitamura Y, Yoshida N, Kikutani H, Kishimoto T. Defects of B-cell lymphopoiesis and bonemarrow myelopoiesis in mice lacking the CXC chemokine PBSF/SDF-1. Nature. 1996; 382:635-638.

22. Tachibana K, Hirota S, Iizasa H, Yoshida H, Kawabata K, Kataoka Y, Kitamura Y, Matsushima K, Yoshida N, Nishikawa S, Kishimoto T, Nagasawa T. The chemokine receptor CXCR4 is essential for vascularization of the gastrointestinal tract. Nature. 1998; 393:591-594. 
23. Zou YR, Kottman AH, Kuroda M, Taniuchi I, Littman DR. Function of the chemokine receptor CXCR4 in heaematopolesis and in cerebellar development. Nature. 1998; 393:595-599.

24. Ma Q, Jones D, Borghesani PR, Segal RA, Nagasawa T, Kishimoto T, Bronson RT, Springer TA. Impaired B-lymphopoiesis, myelopoiesis, and derailed cerebellar neuron migration in CXCR4-and SDF-1-deficient mice. Proc Natl Acad Sci U S A. 1998; 95:9448-9453.

25. Bourquin F, Riezman H, Capitani G, Grütter MG. Structure and function of sphingosine-1-phosphate lyase, a key enzyme of sphingolipid metabolism. Structure. 2010; 18:1054-1065.

26. Lemoli RM, Ferrari D, Fogli M, Rossi L, Pizzirani C, Forchap S, Chiozzi P, Vaselli D, Bertolini F, Foutz T, Aluigi M, Baccarani M, Di Virgilio F. Extracellular nucleotides are potent stimulators of human hematopoietic stem cells in vitro and in vivo. Blood. 2004; 104:1662-1670.

27. Rossi L, Manfredini R, Bertolini F, Ferrari D, Fogli M, Zini R, Salati S, Salvestrini V, Gulinelli S, Adinolfi E, Ferrari S, Di Virgilio F, Baccarani M, et al. The extracellular nucleotide UTP is a potent inducer of hematopoietic stem cell migration. Blood. 2007; 109:533-542.

28. Kronlage M, Song J, Sorokin L, Isfort K, Schwerdtle T, Leipziger J, Robaye B, Conley PB, Kim HC, Sargin S, Schön P, Schwab A, Hanley PJ. Autocrine purinergic receptor signaling is essential for macrophage chemotaxis. Sci Signal. 2010; 3:ra55.

29. Ratajczak MZ, Kim CH, Janowska-Wieczorek A, Ratajczak J. The Expanding Family of Bone Marrow Homing Factors for Hematopoietic Stem Cells: Stromal Derived Factor 1 Is Not the Only Player in the Game. The Scientific World Journal. 2012; :2012.

30. Schneider G, Glaser T, Lemeu C, Abdelbasit Ismail A, Sellers ZP, Moniuszko M, Ulrich H, Ratajczak MZ. Extracellular nucleotides as novel, underappreciated prometastatic factors that stimulate purinergic signaling in human lung cancer cells. Molecular Cancer. . in press.

31. Adams GB, Chabner KT, Alley IR, Olson DP, Szczepiorkowski ZM, Poznansky MC, Kos CH, Pollak MR, Brown EM, Scadden DT. Stem cell engraftment at the endosteal niche is specified by the calcium-sensing receptor. Nature. 2006; 439:599-603.

32. Ratajczak MZ. A novel view of the adult bone marrow stem cell hierarchy and stem cell trafficking. Leukemia. 2015; 29:776-782.

33. Wysoczynski M, Reca R, Ratajczak J, Kucia M, Shirvaikar N, Honczarenko M, Mills M, Wanzeck J, Janowska-Wieczorek A, Ratajczak MZ. Incorporation of CXCR4 into membrane lipid rafts primes homing-related responses of hematopoietic stem/progenitor cells to an SDF-1 gradient. Blood. 2005; 105:40-48.

34. Wu W, Kim CH, Liu R, Kucia M, Marlicz W, Greco N, Ratajczak J, Laughlin MJ, Ratajczak MZ. The bone marrow-expressed antimicrobial cationic peptide LL-37 enhances the responsiveness of hematopoietic stem progenitor cells to an SDF-1 gradient and accelerates their engraftment after transplantation. Leukemia. 2012; 26:736-745.

35. Lee HM, Wu W, Wysoczynski M, Liu R, Zuba-Surma EK, Kucia M, Ratajczak J, Ratajczak MZ. Impaired mobilization of hematopoietic stem/progenitor cells in C5-deficient mice supports the pivotal involvement of innate immunity in this process and reveals novel promobilization effects of granulocytes. Leukemia. 2009; 23:2052-2062.

36. Hoggatt J, Mohammad KS, Singh P, Hoggatt AF, Chitteti BR, Speth JM, Hu P, Poteat BA, Stilger KN, Ferraro F, Silberstein L, Wong FK, Farag SS, Czader M, Milne GL, Breyer RM, Serezani CH, Scadden DT, Guise T, Srour EF, Pelus LM. Differential Stem and Progenitor Cell Trafficking by Prostaglandin E2. Nature. 2013; 495:365-369.

37. Wysoczynski M, Reca R, Lee H, Wu W, Ratajczak J, Ratajczak MZ. Defective engraftment of C3aR-/hematopoietic stem progenitor cells reveals a novel role of the $\mathrm{C} 3 \mathrm{a}-\mathrm{C} 3 \mathrm{aR}$ axis in bone marrow homing. Leukemia. 2009; 23:1455-1461.

38. Reca R, Mastellos D, Majka M, Marquez L, Ratajczak J, Franchini S, Glodek A, Honczarenko M, Spruce LA, Janowska-Wieczorek A, Lambris JD, Ratajczak MZ. Functional receptor for $\mathrm{C} 3 \mathrm{a}$ anaphylatoxin is expressed by normal hematopoietic stem/progenitor cells, and C3a enhances their homing-related responses to SDF-1. Blood. 2003; 101:3784-3793.

39. Sbaa-Ketata E, Courel MN, Delpech B, Vannier JP. Hyaluronan-derived oligosaccharides enhance SDF-1dependent chemotactic effect on peripheral blood hematopoietic CD34(+) cells. Stem Cells. 2002; 20:585-587.

40. Avigdor A, Goichberg P, Shivtiel S, Dar A, Peled A, Samira S, Kollet O, Hershkoviz R, Alon R, Hardan I, Ben-Hur H, Naor D, Nagler A, et al. CD44 and hyaluronic acid cooperate with SDF-1 in the trafficking of human CD34+ stem/progenitor cells to bone marrow. Blood. 2004; 103:2981-2989.

41. Shirvaikar N, Marquez-Curtis LA, Ratajczak MZ, JanowskaWieczorek A. Hyaluronic acid and thrombin upregulate MT1-MMP through PI3K and Rac-1 signaling and prime the homing-related responses of cord blood hematopoietic stem/progenitor cells. Stem Cells Dev. 2011; 20:19-30.

42. Darzynkiewicz Z, Balazs EA. Genome integrity, stem cells and hyaluronan. Aging (Albany NY). 2012; 4:78-88. 